\title{
Identification of Rh alloantibody in Thalassaemia Patients
}

\author{
NAHID SULTANA,${ }^{1}$ ATIAR RAHMAN,${ }^{2}$ FATEMA EASMIN,${ }^{1}$ MD. MAZHARUL HOQUE, ${ }^{3}$ KASHFIA ISLAM, ${ }^{4}$ SONIA \\ SHORMIN, ${ }^{1}$ JOLLY BISWAS ${ }^{5}$
}

\begin{abstract}
:
Summary: Thalassaemiais a congenital hemolytic disorder caused by partial or complete deficiency of $\alpha$ or $\beta$ globin chain synthesis. The disease is treated by lifelong red cell transfusion. So they are at high risk of developing allo-antibodies, resulting difficult to obtain compatible blood, results in, haemolysis \& occasionally life threatening events.
\end{abstract}

Objectives: To find out the frequency of Rhesus alloantibodies among the thalassaemic patients.

Methods: This cross sectional study was done in the department of transfusion medicine in Bangabandhu Sheikh Mujib Medical University from 01-07-2010 to 03-07-20II. Sample size was 100 and the data was collected by face to face interview. Purposive sampling method was applied using inclusion \& exclusion criteria. Statically analysis of the result was obtained by using window based computer software devised with Statistical Packages for Social Sciences (SPSS- I5) (SPSS Inc, Chicago, IL, USA).

Result: In the present study all respondent were $R h$ D-positive. Out of 100 respondents 2 (2.0\%) had positive direct Coomb'sand 6 (6.0\%) had positive indirect Coomd's test. Out of 6 respondent with Rhesus all-antibody, 4 (66.7\%) had anti E antibody, I(I6.7\%) had anti $c$ antibody and I (I6.7\%) had non specific antibody.

Conclusion: In this study among the 100 respondents of thalassaemic patients who receive regular blood transfusion 6 (6.0\%) had developed rhesus allo-antibody among with the most common was Anti E antibody $4(66.7 \%)$. Such information may enable understanding and prevention of this serious and common complication.

Key words: DCT (Direct Coomb's Test), ICT (Indirect Coomb's Test), Rh (Rhesus).

\section{Introduction:}

Thalassemia is an inherited blood disease. It is a serious public health problem throughout the Mediterranean region, the Middle East and the Indian subcontinent, as well as in Southeast Asia and out of approximately 300 million carriers of this hemoglobin disorder worldwide, 55 million live in Southeast Asia. ${ }^{1}$ Thalassemias and hemoglobinopathies are the most common single-gene disorders in humans ona worldwide basis). ${ }^{2,3}$ Thalassemia is acongenital haemolytic disorder caused by partial or complete deficiency of $\alpha$-or $\beta$ -

1. Medical Officer of Transfusion Medicine, Bangabandhu Sheikh Mujib Medical University (BSMMU), Dhaka.

2. Assistant Professor of Transfusion Medicine, BSMMU, Dhaka.

3. Professor of Transfusion Medicine, Dhaka Medical College Hospital, Dhaka.

4. Student of MD (Final part) Transfusion Medicine, BSMMU, Dhaka.

5. Professor \& Chairman of Transfusion Medicine, BSMMU, Dhaka.

Corresponding author: Dr. Nahid Sultana, Medical Officer of Transfusion Medicine, Bangabandhu Sheikh Mujib Medical University, Dhaka. globin chain synthesis. ${ }^{2,4}$ The most severe forms of $\beta$ thalassemia major present within the first year of life with severe anaemia and failure to thrive. The disease is treated by lifelong red cell transfusion. Regular transfusions are essential for patients with thalassemia to maintain growth and development during childhood and to sustain good quality of life during adulthood. ${ }^{4}$ The mainstay of therapy fo severe beta-thalassaemia syndromes is periodic blood transfusions. ${ }^{5}$ Thalassemic patients receiving. Multiple transfusions are at high risk of developing alloantibodies. ${ }^{3,4,6}$ They are generally given to correct the anemia, prevent ineffective erythropoiesis and improve growth and development. $^{5}$

It is estimated by the WHO, the World Bank, and other international agencies that there is a massive increase in the number of patients with different forms of thalassemia in many emerging countries and it is imperative to establish more surveys of the frequency of the disease and set up centers for its control and management. ${ }^{2}$ Despite there being numerous foreign epitopes on essentially all transfusions of nonautologous RBCs, transfusion is not a highly 
immunogenic stimulus. Even in response to multiple transfusions, alloimmunization to alloantigens on transfused RBCs has an overall frequency of approximately $2-6 \% 6$.The development of erythrocyte alloantibodies complicates transfusion therapy in patients with thalassemia. ${ }^{4,7} \mathrm{The} \mathrm{Rh}$ and Kell system alloantibodies are most frequent. However, in a majority of the alloimmunized patients, usually one alloantibody is detected. Patients with alloantibodies against one blood group system are prone to the development of alloantibodies to other blood group systems due to genetic and acquired patient-related factors. ${ }^{6}$

Alloimmunization to erythrocyte antigens is a frequent complication in $\&$ transfusion-dependent thalassemia. ${ }^{4}$ This type of sensitization results in difficulty obtaining compatible blood, transfusion reactions, haemolysis and occasionally life-threatening events. Thalassemia is a relatively common condition and it is well known that the development of erythrocyte alloantibodies complicates transfusion therapy for this disorder. ${ }^{4}$ Antibodies to some blood group antigens frequently causehemolysis (clinically significant, e.g. ABO, Rh, Kell, Kidd, Duffy, MNSs, Lewis), whereas others cause no deleterious effect (clinically insignificant, e.g. Anti-LW, Ge, Xg, Sc, Chido, Rogers, Bg). The prevalence of alloantibodies in thalassemics in India is 4-7\%. The Rh and Kell system alloantibodies are most frequent. ${ }^{5,6}$ In a study found significant levels of red cell alloantibodies were present in 11 patients $(25 \%)$, and 8 patients $(18 \%)$ had red cell autoantibodies. ${ }^{8}$

The development of erythrocyte alloantibodies complicates transfusion therapy inpatients with thalassemia. However, no data are available on the frequency of erythrocyte alloimmunization in patients with transfusion-dependent thalassemia in Bangladesh. In this study, we will investigate the frequency of alloantibodies among patients receiving regular red cell transfusions for thalassemia.

\section{Methodology:}

This is a cross sectional studywas conducted in the Department of Transfusion Medicine, Bangabandhu Sheikh Mujib Medical University from $1^{\text {st }}$ July 2010 to $30^{\text {th }}$ June 2011. 100 thalassaemia patients were seen and purposive sampling method was applied including both sex and rhesus D antigen positive with age group 2-50 years. Data was collected by face to face interview and stastical analyses of the results were obtained by using window based computersoftware devised with Statistical Packages for Social Sciences(SPSS-15)(SPSS Inc, Chicago, IL, USA).

\section{Result:}

Table I

Distribution of age of the respondents

\begin{tabular}{lcc}
\hline (Age in year) & Frequency & Percent \\
\hline $2-10$ & 52 & 52.0 \\
$11-20$ & 16 & 16.0 \\
$21-30$ & 14 & 14.0 \\
$31-40$ & 09 & 09.0 \\
$41-50$ & 09 & 09.0 \\
\hline Total & 100 & 100.0 \\
\hline
\end{tabular}

Mean \pm SD (Range) $16.75 \pm 14.15$ (5-50)

Table I shows the distribution of age of the respondents. Mean \pm SD age of therespondents was $16.75 \pm 14.15$ with a range of 2 to 50 years. $52(52,0 \%)$ of the respondents were in the age group of 2-10 years followed by the age group of $10-20$ years $(16.0 \%)$. Other age group 21 to 30 years, 31 to 40 years and $41-50$ years were $14(14.0 \%), 9(9.0 \%)$ and 9 $(9.0 \%)$ respectively.

Table II

Distribution of sex of the respondents

\begin{tabular}{lcc}
\hline Sex & Frequency & Percent \\
\hline Male & 49 & 49.0 \\
Female & 51 & 51.0 \\
\hline Total & 100 & 100.0 \\
\hline Male : Female & $\mathbf{1 : 1 . 0 4}$ &
\end{tabular}

Table-II shows the distribution of sex of the respondents. Out the 100 respondents 49 were male and 51 were female, Male female ratio was 1:1.04.

Table III

Distribution of frequency of blood transfusion

\begin{tabular}{lcc}
\hline Blood transfusion & Frequency & Percent \\
\hline Weekly & 10 & 10.0 \\
Monthly & 70 & 70.0 \\
Irregular & 20 & 20.0 \\
\hline Total & $\mathbf{1 0 0}$ & $\mathbf{1 0 0 . 0}$ \\
\hline
\end{tabular}


Table-III shows the distribution of frequency of blood transfusion. In $70.0 \%$ of respondents frequency of blood transfusion was monthly followed by irregular frequency (20.0\%). Frequency of blood transfusion of rest $10.0 \%$ was weekly.

Table IV

Adverse effect during blood transfusion

\begin{tabular}{lcc}
\hline Adverse effect & Frequency & Percent \\
\hline Present & 40 & 40.0 \\
Absent & 60 & 60.0 \\
Total & 100 & 100.0 \\
\hline
\end{tabular}

Table-IV shows the distribution of adverse effect during blood transfusion. Out of 100 respondents adverse effect present in $40.0 \%$ and $60.0 \%$ had no adverse effect.

Table V

Distribution of type of adverse effects among sufferer of the respondents $(n=40)$

\begin{tabular}{|c|c|c|}
\hline Type & Frequency & Percentage \\
\hline - Chills and rigar & 15 & 37.5 \\
\hline - Fever & 18 & 45.0 \\
\hline - Urticaria & 6 & 15.0 \\
\hline - High coloured urine & 1 & 2,5 \\
\hline Total & 40 & 100.0 \\
\hline
\end{tabular}

Table- $\mathrm{V}$ shows the distribution of time of occurrence of adverse effect during blood transfusion. Out of 40 respondents that developed adverse effect chills and rigor $15(37.5 \%)$, fever $18(45.0 \%)$, urticaria $6(15,0 \%)$ and high coloured urine $1(2.5 \%)$.

Table VI

Distribution of alloantibody by Coombs test among the respondents

\begin{tabular}{lcc}
\hline Coombs' test & Frequency & Percent \\
\hline DCT & & \\
- Positive & 02 & 02.0 \\
- Negative & 98 & 98.0 \\
ICT & & \\
- Positive & 06 & 06.0 \\
- Negative & 94 & 94.0 \\
\hline
\end{tabular}

DCT: Direct Coombs' test; ICT: Indirect Coombs' test.
Table VII shows the distribution of alloantibody by Coombs' test among the respondents. Out of 100 respondents $2(2.0 \%)$ had positive direct Coombs' test and $6(6.0 \%)$ had indirect Coombs' test.

Table VII

Distribution of Rhesus alloantibody among the respondents $(n=6)$

\begin{tabular}{lcc}
\hline Rhesus alloantibody & Frequency & Percent \\
\hline Anti E & 04 & 66.7 \\
Anti c & 01 & 16.7 \\
Anti C & nil & nil \\
Anti e & nil & nil \\
Non specific antibody & 01 & 16.7 \\
\hline Total & 06 & 100.0 \\
\hline
\end{tabular}

Table 8 shows the distribution of Rhesus alloantibody among the respondents. Out of 6 respondents with rhesus alloantibody, 4 (66.7\%) had anti E antibody, 1 (16.7\%) had $1(16.7 \%)$ had non specific antibody. No respondents were presented with anti $\mathrm{C}$ antibody and antic antibody.

\section{Discussion:}

Thalassemia is one of the most common genetic disorders. It is estimated that 300,000 infants are born with major hemoglobinopathies worldwide in each year of whom 60,000 to 70,000 are beta thalassemia major cases especially inthe Mediterranean area, Middle East, Far East, and East Asia. ${ }^{9}$ Major advances have occurred in the treatment and prevention of thalassemia major. ${ }^{10}$ The survival of patients increased significantly with the improvement of conventional therapy and some of them reach mature age and are exposed to higher risk of new complications. ${ }^{11}$ Almost all patients with thalassaemia major require blood transfusion within the first two to three years of life to prevent severe anaemia and its physical consequences. ${ }^{12}$ Life-long transfusion remains the main treatment for severe thalassemia. The development of anti-RBC antibodies, (alloantibodies and or autoantibodies) can significantly complicate transfusion therapy. ${ }^{13}$ It is well known that the development of erythrocyte alloantibodies complicates transfusion therapy. ${ }^{4}$ Alloimmunization and autoimmunization are common, serious complications in Asian thalassemia patients, who are affected by donor-recipient RBC antigen mismatch and immunological factors. ${ }^{4,13}$ Alloimmunization to erythrocyte antigens is a frequent complication in transfusion-dependent thalassemia. This type of sensitization 
results in difficulty obtaining compatible blood, transfusion reactions, haemolysis and occasionally life-threatening events. ${ }^{4}$

1. The RBC antigenic difference between the blood donor and therecipient; 2 , The recipient's immune status; 3 . The immunomodulatory effect/ of the allogeneic blood transfusions on the recipient's immune system are thethree factors for alloimmunization. ${ }^{13}$

Mean \pm SD age of the respondents was $16.75 \pm 14.15$ with a range of 2 to 50 years. $52(52.0 \%)$ of the respondents were in the age group of 2 to 10 years followed by the age group of 11 to 20 years $(16.0 \%)$. Other age group 21 to 30 years, 31 to 40 years and 41 to 50 years were $14(14.0 \%), 9(9.0 \%)$ and $9(9.0 \%)$ respectively ${ }^{10}$ showed that in 1973 , a survey wasdone of the ages of 243 living patients with thalassemia major followed at 12 centers in the United States and Canada. $22.0 \%$ percent were younger than 5 years and $2.1 \%$ were older than 25 years (mean 11.4 \pm 6.7 [SD] years). In1985, there were 303 patients at the same centers; $11 \%$ were younger than 5 years and $7.9 \%$ were older than 25 years (mean 14.2 \pm 7.3 years.In a study ${ }^{12}$ from the 12 reference hospitals for two decades show increasing mean ages of patients in 1973, $11.4 \pm 6.7$ years; in $1985,14.2 \pm 7.3$ years; and in 1993, 16.H9.2 years. In Bangladesh a study by ${ }^{21}$ of 152 with thalassaemic patients found the mean age of $6.8 \pm 3.6$ years. In a study ${ }^{20}$ found the mean \pm SD age of patients was $13.0 \pm 6.1$ years and ranged from 2 to 26 years. Mean \pm SD age of the respondents in the studies by ${ }^{12,20}$ found similarity with the preserlt study. But the study by ${ }^{21}$ were found dissimilarity with the present study.

In this present study out of 100 respondents 49 were male and 51 were female. Male to female ratio was $1: 1.04 \cdot{ }^{13}$ in a study of 64 patients found 37 were females and 27 were males. Male to female ratio was $1: 1.37 .{ }^{20}$ In a study of 121 patients $66(54.5 \%)$ were females and $55(45.5 \%)$ were males. Male to female ratio of the present study comparable with the studies of ${ }^{13,20}$.

A low rate of alloimmunization may be expected when there is homogeneity of RBC antigens between the blood providers and recipients. ${ }^{13}$ In this study $2(2.0 \%)$ had positive direct Coombs' test and $6(6.0 \%)$ hadindirect Coombs' test. In a study $^{13}$ showed that the incidenceof red cell alloimmunization among Asian patients in the United States was $20.8 \%$, which was attributed majnly to differences in the distribution of red cell antigens between Caucasian donors and Asian recipients. ${ }^{13}$

Data on presumed homogenous populations studied by ${ }^{14}$ in Greece and ${ }^{15}$ in Italy showed an overall low rate $(5 \%$ to
$10 \%$ ) of alloimmunization. ${ }^{13}$ Studies have reported a rate of red cell alloimnmnization ranging from 5 to $20 \% 16,17,18,19,20$ in their study reported direct or indirect antiglobulin tests were positive in $5(62.5 \%)$ patients with alloimmunization. Reported $^{22} 161$ patients with $4.97 \%$ alloimmunization and positive direct Coombs test in $3(1.87 \%)$ patients.

Out of 6 respondents with rhesus alloantibody, 4 (66.7\%) had anti E antibody, 1 (16.7\%) had Anti c and 1 (16.7\%) had non specific antibody. No respondents were presented with anti $\mathrm{C}$ antibody and anti e antibody. Singer et al. (2000) in their study found the high frequency (21\%) of anti-E antibodies among the Asian patients. Wang et al. (2006) in a study among the 30 patients tested, found 11 (37\%) had alloantibodies, including six females and five males. All alloantibodies were clinically significant specificities and included four casesof anti-E; two cases of anti $\mathrm{c}$ and one case of anti- ${ }^{4} \mathrm{Mia}$, anti-D and anti-S. In their study three patients had two alloantibodies. In the present study amongthe respondents with rhesus alloantibody anti $\mathrm{E}$ antibody were most frequent which can be compared with the study by. ${ }^{13,4}$

\section{Conclusion:}

In this study among the 100 respondents of thalasaemic patients who receive regular blood transfusion, $2(2.0 \%)$ had positive direct Coombs' test and $6(6.0 \%)$ had positive indirect Coombs' test. Anti $\mathrm{E}$ antibody is the most common rhesus alloantibody found in this study.

Due to the short study period, more sample number and further investigation could not be achieved. With the growing knowledge base of the immune effects of current blood transfusion and limited data on the immune status of thalassemia patients, a large study addressing the complex interaction of these factors is needed. Such information may enable understanding and prevention of this serious and common complication.

\section{Recommendation:}

All thalasaemic patients should have done phenotype \& Genotype prophylactically before planning of transfusion.

Blood should be cross-matched by ICT method. If antibody is identified then corresponding antigen negative blood should be transfused.

Large scale study is recommended.

\section{Conflict of Interest : None}

\section{References}

1. Thavorncharoensap M, Torcharus K, Nuchprayoon I, Riewpaiboon A, KaemthongIndaratna K, Ubol B. Factors affecting health-related quality of lifein Thai children with thalassemia. BMC Blood Disord. 2010;10:1. 
2. Liu KZ, Tsang KS, Li CK, Shaw RA, MantschHH. $\beta$ Thalassemia.Clinical Chemistry. 2003;49:1125-1132.

3. Noor Haslina MN, Ariffin N, IllimiHayati I, Rosline $\mathrm{H}$. Red cell $\mathrm{H}$ autoantibodies among thalassaemia patients in Hospital UntversitiSainsMalaysia. Singapore Med J 2007;48(10):922-925.

4. Wang L-Y, Liang D-C, Liu H-C, Chang F-C, Wang C-L, Chan Y-S, Lin M.Alloimmunization among patients with transfusion-dependent thalassemia in Taiwan. Transfusion Medicine 2006;16:200-203.

5. Bashawri LAM, Ahmed MS, El-Fawaz N, AL-QataryAAK, Ahmed MA.Red Cell Alloimmunization in Thalassaemia Patients. Bahrain Medical Bulletin2005;27(2).

6. Arora S, Dhawan HK, Sachdev S, Patidar G, Sharma RR, Marwaha N, Trehan A, MarwahaRK. Alloimmunization to both Rli and Kell system antigens (anti-C and anti-K) in a young thalassemic patient, Indian J PatholMicrobiol 2010;53:889-90.

7. Canatan D, Acar N, Kilic B. Rh Subgroups and Kell Antigens in Patients with Thalassemia and in Donors in Turkey. Tr. J. of Medical Sciences 1999;29:155-157.

8. Kidson-Gerber GL, Francis S,t Lindeman R. Management and clinical outcomes of transfusion-dependent thalassaemia major in an Australian tertiary referral clinic. MJA 2008;188 (2):72-75.

9. Abolghasemi H, Amid A, Zeinali S, Radfar MH, Eshgh'i P, Rahiminejad MS. Thalassemia in Iran Epidemiology, Prevention, and Management. J PediatrHematolOncol 2007;29:233-238

10. Pearson HA, Guiliotis DK, Rink L, Wells JA. Patient age distribution in thalassemia major:changes from 1973 to 1985. Pediatrics 1987;80(1):53-7.

11. Tchakurova P, Zdravkova Z, Thacurov R, Kaleva D, Mutlu F, Yovtcheva V, Petkov G. Late bone changes in patients with homogygous thalassaemia. Trakia Journal of Sciences 2003;1(1):49-52.

12. Pearson HA, Cohen AR, GiardinaPJ, KazazianHH. The changing profile of / homozygous beta-thalassemia: demography, ethnicity, and age distribution of current North American patients and changes in two decades. Pediatrics. 1996;97(3):352-6.
13. Singer ST, Wu V, Mignacca R, Kuypers FA, Morel P, Vichinsky EP.Alloimmunization and erythrocyte autoimmunization $\mathrm{m}$ transfusion-dependentthalassemia patients of predominantly Asian descent.Blood. 2000;96:3369-3373

14. Michail-Merianou V, Pamphili-Panousopoulou L, PiperiLowes L, Pelegrinis E, Karaklis A. Alloimmunization to red cell antigens in thalassemia:comparative study of usual versus better-match transfusion programmes. Vox Sang. 1987;52:95-98.

15. Spanos, T., Karageorga, M., Ladis, V., Peristeri, J., Hatziliami, A. andKattamis, C. Red Cell Alloantibodies in Patients with Thalassemia. VoxSanguinis 1990;58:50-55.

16. Coles, S.M., Klein, H.G. \& Holland, P.V. (1981) Alloimmunization in two multitrans fused patients populations. Transfusion, 21,462-466.

17. Sirchia, G., Zanella, A., Parravicini, A., Morelati, F., Rebulla, P. \&Masera, G, (1985) Red cell alloantibodies in thalassemia major. Results of an Italian cooperative study. Transfusion, $25,110-112$

18. Walker, R.H., Lin, D.T. \&Hartrick, M.B. (1989) Alloimmunization following 4,blood transfusion. Archives of Pathology and Laboratory Medicine, 113, 254-261.

19. Hmida, S., Mojaat, N., Maamar, M., Bejaoui, M., Mediouni, M. \&Boukef, K.(1994) Red cell alloantibodies in patients with hemoglobinopathies. Nouvelle revue francaised'hematologie, 36, 363-366.

20. Shamsian BS, Arzanian MT, Shamshiri AR AlaviSamin, Khojasteh O. Frequency of Red Cell Alloimmunization in Patients with (3 Major Thalassemia in an Iranian Referral Hospital. Iran J Pediatr 2008;18 (2):149-153.

21. Mollah AH, Nahar N, Siddique MA, Anwar KS, Hassan T, Azam MG. Common transfusion-transmitted infectious agents among thalassaemic children in Bangladesh. J Health PopulNutr. 2003 Mar;21(1):67-71.

22. Bhatti FA, Salamat N, Nadeem A, et at. Red cell immunization in beta Thalassemia major. J Coll Physicians Surg Pak. 2004; 